\title{
Phylogenomic reconstruction of lactic acid bacteria: an update
}

\author{
Zhi-Gang Zhang ${ }^{1+}$, Zhi-Qiang Ye $\mathrm{Y}^{1,3+}, \mathrm{Li} \mathrm{Yu}^{2^{*}}$, Peng Shi ${ }^{1^{*}}$
}

\begin{abstract}
Background: Lactic acid bacteria ( $L A B)$ are important in the food industry for the production of fermented food products and in human health as commensals in the gut. However, the phylogenetic relationships among $L A B$ species remain under intensive debate owing to disagreements among different data sets.

Results: We performed a phylogenetic analysis of $L A B$ species based on 232 genes from 28 LAB genome sequences. Regardless of the tree-building methods used, combined analyses yielded an identical, well-resolved tree topology with strong supports for all nodes. The LAB species examined were divided into two groups. Group 1 included families Enterococcaceae and Streptococcaceae. Group 2 included families Lactobacillaceae and Leuconostocaceae. Within Group 2, the LAB species were divided into two clades. One clade comprised of the acidophilus complex of genus Lactobacillus and two other species, $L b$. sakei and $L b$. casei. In the acidophilus complex, Lb. delbrueckii separated first, while $L b$. acidophilus/Lb. helveticus and Lb. gasseri/Lb. johnsonii were clustered into a sister group. The other clade within Group 2 consisted of the salivarius subgroup, including five species, Lb. salivarius, Lb. plantarum, Lb. brevis, Lb. reuteri, Lb. fermentum, and the genera Pediococcus, Oenococcus, and Leuconostoc. In this clade, Lb. salivarius was positioned most basally, followed by two clusters, one corresponding to $\mathrm{Lb}$. plantarum/Lb. brevis pair and Pediococcus, and the other including Oenococcus/Leuconostoc pair and $L b$. reuteri/Lb. fermentum pair. In addition, phylogenetic utility of the 232 genes was analyzed to identify those that may be more useful than others. The genes identified as useful were related to translation and ribosomal structure and biogenesis (TRSB), and a three-gene set comprising genes encoding ultra-violet resistance protein B (uvrB), DNA polymerase III (po/C) and penicillin binding protein $2 \mathrm{~B}(\mathrm{pbp} B)$.

Conclusions: Our phylogenomic analyses provide important insights into the evolution and diversification of $L A B$ species, and also revealed the phylogenetic utility of several genes. We infer that the occurrence of multiple, independent adaptation events in $\angle A B$ species, have resulted in their occupation of various habitats. Further analyses of more genes from additional, representative $L A B$ species are needed to reveal the molecular mechanisms underlying adaptation of $L A B$ species to various environmental niches.
\end{abstract}

\section{Background}

Lactic acid bacteria (LAB) are Gram-positive bacteria that have been widely used as starter or nonstarter cultures in the plant, meat, and dairy fermentation, and also as probiotic bacteria in human gastrointestinal tract

\footnotetext{
* Correspondence: yuli1220@yahoo.com.cn; ship@mail.kiz.ac.cn

+ Contributed equally

'State Key Laboratory of Genetic Resources and Evolution, Laboratory of Evolutionary and Functional Genomics, Kunming Institute of Zoology, Chinese Academy of Sciences, Kunming 650223, PR China

${ }^{2}$ Laboratory for Conservation and Utilization of Bio-resource \& Key Laboratory for Microbial Resources, Ministry of Education, Yunnan University, PR China

Full list of author information is available at the end of the article
}

contributing to pathogen inhibition and immunomodulation. At present, nearly $400 \mathrm{LAB}$ species have been recognized [1]. They are generally classified into four families and seven genera, as follows: family Lactobacillaceae (genera Lactobacillus and Pediococcus), family Leuconostocaceae (genera Oenococcus and Leuconostoc), family Enterococcaceae (genus Enterococcus) and family Streptococcaceae (genera Lactococcus and Streptococcus) [2-4]. Phylogenetic relationships among the LAB species have been hotly disputed. One of the foremost debates in LAB phylogeny concerns the species in the genera Lactobacillus, Pediococcus, Oenococcus, and Leuconostoc, which belong to family Lactobacillaceae and Leuconostocaceae,
C Biomed Central

() 2011 Zhang et al; licensee BioMed Central Ltd. This is an Open Access article distributed under the terms of the Creative Commons Attribution License (http://creativecommons.org/licenses/by/2.0), which permits unrestricted use, distribution, and reproduction in any medium, provided the original work is properly cited. 
due to the severe disagreements arising from analyses of different data sets [2-11]. In the genus Lactobacillus, there are uncertainties about the interspecies affinities within the acidophilus complex [8] that consists of five species Lb. gasseri, Lb. johnsonii, Lb. acidophilus, Lb. helveticus and $L b$. delbrueckii. In particular, the divergence between Lb. gasseri/Lb. johnsonii, Lb. acidophilus/Lb. helveticus and $L b$. delbrueckii remains unresolved. Based on the analyses of a $16 \mathrm{~S}$ rRNA gene and a few nuclear genes $[3,5,7,10,12]$ and that of 32 ribosomal proteins [9], Lb. delbrueckii was found to be more closely associated with $L b$. acidophilus/Lb. helveticus than with $L b$. gasseri/ $L b$. johnsonii. However, a recent study using 141 core proteins from 17 LAB species suggested that $L b$. delbrueckii diverged earliest within the acidophilus complex, while Lb. acidophilus/Lb. helveticus and Lb. gasseri/Lb. johnsonii clustered into a sister group [8].

Although the paraphyly of Lactobacillus species is well-established, a general consensus for the placement of the Lactobacillus species, e.g., Lb. salivarius, Lb. plantarum, Lb. brevis, Lb. reuteri, Lb. sakei, and Lb. casei, and their relationship to the genera Pediococcus, Oenococcus, and Leuconostoc has not yet emerged in the 'salivarius' subgroup. For example, in the analysis of four subunits of RNA polymerase, the clade uniting $L b$. sakei and $L b$. case $i$ is placed at the most basal position, followed by $L b$. salivarius. Pediococcus is sister to the clade containing $L b$. plantarum and $L b$. brevis, while Oenococcus/Leuconostoc clusters with $L b$. reuteri [7]. In contrast, an analysis of 141 core proteins suggested that the $L b$. sakei/Lb. casei clade is more related to acidophilus complex, while the other Lactobacillus species and Pediococcus, Oenococcus, as well as Leuconostoc group together, in which Oenococcus/Leuconostoc diverged earliest, followed by Lb. salivarius, Pediococcus, Lb. reuteri, and lastly the species most recently diverged, $L b$. plantarum and $L b$. brevis [8].

These findings highlight the need to gather and analyze larger sequence data sets in order to unravel the phylogenetic relationships among LAB species and clarify specifically those within genera Lactobacillus, Pediococcus, Oenococcus, and Leuconostoc. The increasing availability of LAB genome sequence data provides a good opportunity to understand the evolutionary history of LAB species. In the present study, we studied LAB phylogeny by gathering and analyzing 232 orthologous genes from $28 \mathrm{LAB}$ genome sequences representing all genera from four families. Our objectives were to provide new insights into the relationships of LAB species and to examine the utility of such an analysis in the context of LAB phylogeny, and develop new potential genetic markers for study of LAB systematics. This study not only contributes to clarifying the currently obscure LAB species relationship, but also lays a foundation for further studies on adaptive evolution of LAB species in different environmental niches.

\section{Results and Discussions}

\section{Identification of orthologous genes}

The use of accurate and reliable methods for the identification of orthologous genes is essential for phylogenetic reconstruction based on analyses of large data sets, especially for those using whole genome sequences [13]. In the present study, the strategy of developing potential orthologous gene sets for LAB phylogenomic studies was different from those used in previous LAB analyses. First, in previous studies of LAB phylogeny, less stringent clusters of orthologous groups (COGs) [6] and reciprocal best hits [8] methods were applied to identify putative orthologs. Here, we applied both Inparanoid [14] and MultiParanoid [15] programs to serve this purpose. Inparanoid [14] exploits a BLAST-based strategy to identify orthologs as reciprocal best hits between two species, and applies additional rules to accommodate inparalogs that arise from recent duplication events after speciation. Compared with other methods, including COGs [16] and OrthoMCL [17], Inparanoid's superiority lies in the ability to distinguish orthologs from in-paralogs and out-paralogs (those that arose via ancient duplication event before speciation) [17-21]. MultiParanoid software [15] performs clustering of orthologs and in-paralogs that are shared by more than two species. By using the conservative searching algorithms, we obtained a total of 310 one-to-one protein coding orthologs (Additional file 1 Table S1).

To make our dataset more conservative, we further excluded potentially problematic orthologs such as those with short sequence lengths and those involved in horizontal gene transfer (HGT). These criteria have not yet been used in previous LAB studies. In the end, a total of 232 orthologous genes, including 225 genes that have clear functional definition and 7 genes that have been annotated as hypothetical proteins (Additional file 2 Table S2), were used to reconstruct LAB phylogeny in this study. This dataset of 232 genes included those encoding 135 out of the 141 core proteins of the Claesson's study [8] that were identified by phylogenomic analyses of 17 LAB species genomes. Noticeably, 6 core proteins included in Claesson's study [8] were discovered as in-paralogs here and hence excluded from further analyses. This suggests that our dataset is more conservative and reliable than those from previous studies aimed at inferring LAB phylogeny.

\section{Reconstruction of LAB phylogenomic tree}

Based on the concatenated amino acid alignment of 232 genes, phylogenetic analyses using two gap selection criteria (see Methods) and two tree-building methods, 
partitioned maximum likelihood (ML) and Bayesian analyses, yielded an identical, well-resolved tree topology with strong supports for all nodes (BS > 99\% and PP > 0.99) (Figure 1), suggesting that the accuracy of our phylogenetic inference is independent of tree-building methods. As revealed in Figure 1 the monophyly for families Leuconostocaceae, Enterococcaceae and Streptococcaceae were strongly supported. For Lactobacillaceae, some species were more closely related to Leuconostocaceae than the other Lactobacillaceae species, supporting the paraphyly for family Lactobacillaceae, providing a possibility that Leuconostocaceae and Lactobacillaceae can be combined into a family.

The LAB species were divided into two groups. Group 1 included Enterococcaceae and Streptococcaceae. Group 2 included Lactobacillaceae and Leuconostocaceae. Within Group 1, the monophyly of the genera
Enterococcus, Lactococcus and Streptococcus were strongly supported. In Streptococcus, S. mutans and S. thermophilus were grouped together, and S. gordonii was their sister taxon. The relationships within Group 1 observed here were congruent with two other studies $[5,10]$, but disagreed with the $16 \mathrm{~S}$ rRNA gene tree [22] (Figure 1). Within Group 2, LAB species were divided into two clades. One clade composed of acidophilus complex of genus Lactobacillus and two other Lactobacillus species, $L b$. sakei and $L b$. casei. This result is in contradiction with the RNA polymerase-based study of Liu [7] that suggested that $L b$. sakei and $L b$. casei are more closely related to other Lactobacillus species and the genera Pediococcus, Oenococcus as well as Leuconostoc. However, our results are in agreement with the RNA polymerase trees [5,10], ribosomal-protein tree [9] and the 141-core proteins tree [8]. Of the five recognized Lactobacillus

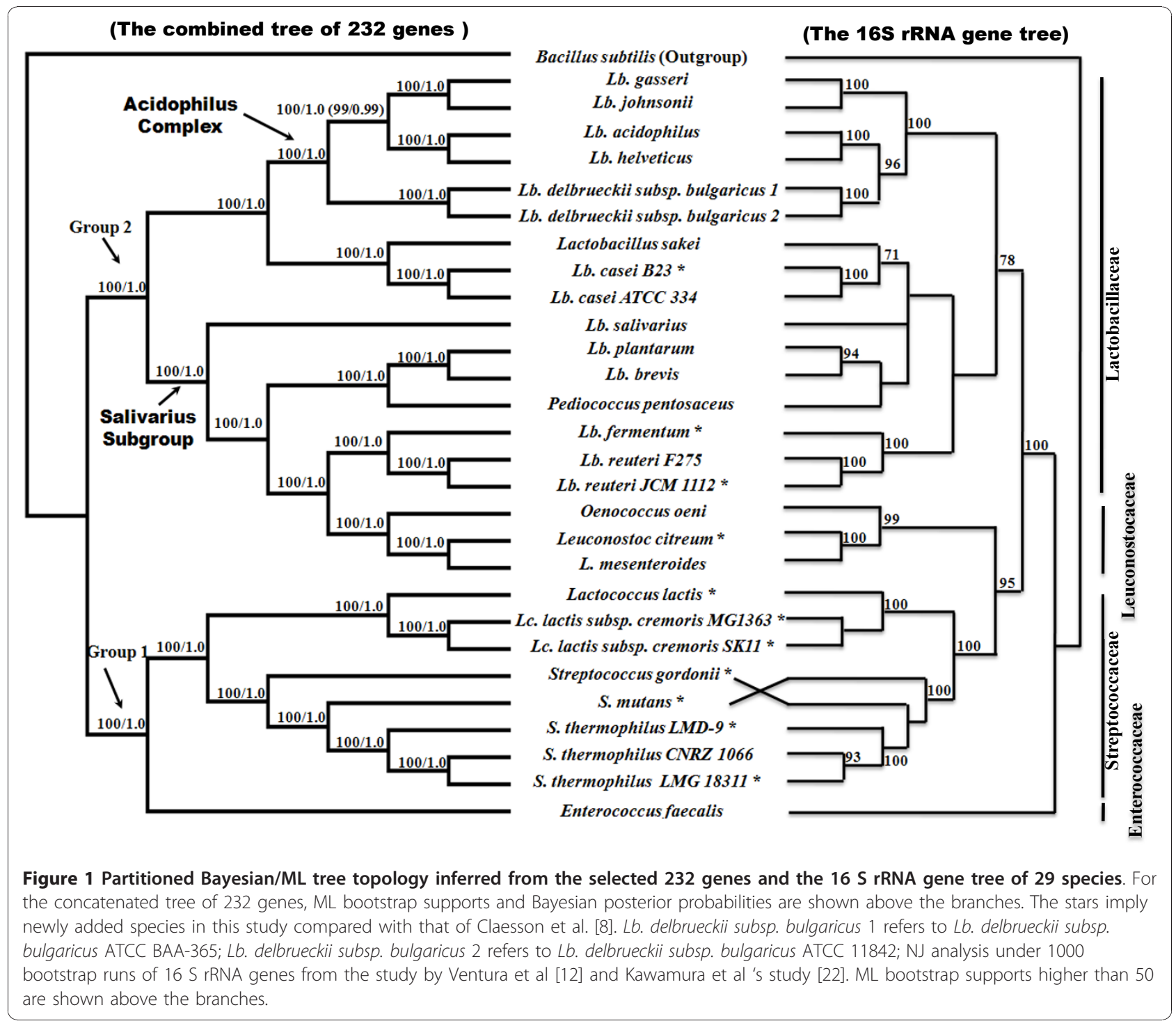


species in the acidophilus complex, our results strongly support the notion that $L b$. delbrueckii separated first, while $L b$. acidophilus/Lb. helveticus and Lb. gasseri/Lb. johnsonii clustered into a sister group. This finding is in accordance with the result derived from the 141-core proteins analyses [8], but disagrees with those derived the single $16 \mathrm{~S}$ rRNA gene $[3,8,12]$ and the nuclear gene analyses $[5,7,10,23]$ as well as that of 32 ribosomal proteins [9], in which $L b$. delbrueckii was seen to be more closely associated with $L b$. acidophilus/Lb. helveticus than $L b$. gasseri/Lb. johnsonii. Five Lactobacillus species, including $L b$. salivarius, $L b$. plantarum, Lb. brevis, Lb. reuteri, $L b$. fermentum, and the genera Pediococcus, Oenococcus, and Leuconostoc constitute the other clade, the 'salivarius' subgroup within Group 2. In this clade, Lb. salivarius was positioned most basally, followed by two distinct clusters, one corresponding to Lb. plantarum/Lb. brevis group and Pediococcus, and the other including Oenococcus/Leuconostoc group and Lb. reuteri/Lb. fermentum group. The basal position of $L b$. salivarius in this clade is consistent with the RNA polymerase tree inferred by Makarova and Koonin [5] as well as by Liu [7], but not with the $16 \mathrm{~S}$ rRNA gene tree [12] and studies by Claesson [8] and Cai [10] that indicated that Oenococcus/Leuconostoc group diverged first. In addition, the grouping of $L b$. plantarum $/ L b$. brevis and Pediococcus observed here is supported in most current studies, but is in contradiction with the recent proposal of the connecting of $L b$. plantarum $/ L b$. brevis and $L b$. reuteri. In the present study, the close relatedness of Oenococcus/ Leuconostoc group and Lb. reuteri/Lb. fermentum is in agreement with RNA polymerase tree inferred by Liu et al. [7]. The possible placement of Oenococcus/Leuconostoc group as the first diverging taxa $[8,10]$ or as the diverging taxa subsequent to Lb. salivarius [5] was not supported here.

Taken together, our study provides new insights into the evolutionary relationships of these LAB species, and helps to resolve the current controversial issues in LAB phylogeny. Depending on the gene segments or genomes and the tree-building methods used, different phylogenetic hypotheses can be obtained. Interestingly, our study demonstrated that different evolutionary rates among sites may also affect LAB phylogenetic reconstruction. When we repeated the phylogenetic analyses by setting a fixed alpha value of gamma distribution in the optimal amino acid substitution model, the species relationships within acidophilus complex, i.e., that among $L b$. gasseri/ $L b$. johnsonii, Lb. acidophilus/Lb. helveticus and Lb. delbrueckii, became unstable and were poorly supported in partitioned ML and Bayesian analyses (data not shown). Therefore, our study revealed that different evolutionary rate among sites is also an important factor in tracing the evolutionary history of LAB species.
Besides the contribution of phylogenetic resolution, our results revealed the presence of independent adaptation to four types of habitat niches in LAB species (Figure 1), involving human gastrointestinal tract, human oral flora, dairy fermentation and other fermentations of beer, wine, plants, or meat (Table 1). For example, within acidophilus complex, $L b$. acidophilus that is isolated from human gastrointestinal tract and $L b$. helveticus that is widely applied to dairy fermentation are more closely related to each other than to the other three Lactobacillus species, suggesting an independent adaptation to their respective niches. The independent adaptation events of $L b$. plantarum to human gastrointestinal tract were also evidenced by transcriptome analyses [24], although $L b$. plantarum strains isolated from the gastrointestinal tract or feces may be derived from human diet and may in fact reflect earlier adaption to other environmental niches such as fermentations of meat, plant, cheese or wine [25]. Otherwise, Lb. brevis is most suitable for meat fermentation in our phylogenetic tree. Given that strains of many LAB species occur in a multitude of ecological niches, further analyses of more genes and functional assays of additional LAB species are needed to reveal the molecular mechanisms underlying the adaptation of LAB species to various environmental survival niches.

\section{Utilities of different genes in LAB phylogeny}

We also evaluated the phylogenetic utility of different genes used here. According to COG annotation [16], we classified 232 genes into four functional categories (Additional file 2 Table S2) relating to: information storage and processing (ISP; 135 genes), cellular processes and signaling (CPS; 49 genes), metabolism (41 genes), and hypothetical proteins (HP; 7 genes). Among them, the genes with ISP function were further divided into translation, ribosomal structure and biogenesis (TRSB; 69 genes), replication/repair/recombination (RRR; 51 genes), and transcription (15 genes). The phylogenetic analyses of LAB were repeated using each of the above six categories of genes individually. Our results suggested that the analyses of RRR (Figure 2), transcription (Figure 3), CPS (Figure 4), metabolism (Figure 5) and HP (Figure 6) genes produced different tree topologies from that of all concatenated genes (Figure 1), while the analyses of TRSB genes yielded identical tree topologies to those shown in Figure 1 suggesting that the TRSB genes are better indicators of LAB phylogeny than are other subsets of genes. The Robinson-Foulds distances analysis (Additional file 3 Table S3) also showed that there are no differences between the tree of TRSB genes and that of all concatenated genes. The differences among tree topologies based on these functional categories can be caused by various factors, including 
Table 1 Summary of 28 LAB taxa and one outgroup (Bacillus subtilis)

\begin{tabular}{|c|c|c|}
\hline Species-Organisms & Association & NCBI RefSeq \\
\hline Bacillus subtilis subsp. subtilis str. 168 & Outgroup & NC_000964 \\
\hline Enterococcus faecalis V583 & gastrointestinal tract bacteria & NC_004668 \\
\hline Lactobacillus acidophilus NCFM & gastrointestinal tract bacteria & NC_006814 \\
\hline Lactobacillus brevis ATCC 367 & other fermentation such as beer, wine, plants, or meat & NC_008497 \\
\hline Lactobacillus casei ATCC 334 & dairy fermentation & NC_008526 \\
\hline Lactobacillus casei BL23 & dairy fermentation & NC_010999 \\
\hline Lactobacillus delbrueckii subsp. bulgaricus ATCC 11842 & dairy fermentation & NC_008054 \\
\hline Lactobacillus delbrueckii subsp. bulgaricus ATCC BAA-365 & dairy fermentation & NC_008529 \\
\hline Lactobacillus fermentum IFO 3956 & other fermentation such as beer, wine, plants, or meat & NC_010610 \\
\hline Lactobacillus gasseri ATCC 33323 & gastrointestinal tract bacteria & NC_008530 \\
\hline Lactobacillus helveticus DPC 4571 & dairy fermentation (Swiss cheese isolate) & NC_010080 \\
\hline Lactobacillus johnsonii NCC 533 & gastrointestinal tract bacteria & NC_005362 \\
\hline Lactobacillus plantarum WCFS1 & Human saliva (first), gut, dairy, wine, plants, or meat & NC_004567 \\
\hline Lactobacillus reuteri F275 & gastrointestinal tract bacteria & NC_009513 \\
\hline Lactobacillus reuteri JCM 1112 & gastrointestinal tract bacteria & NC_010609 \\
\hline Lactobacillus sakei subsp. sakei $23 \mathrm{~K}$ & other fermentation such as beer, wine, plants, or meat & NC_007576 \\
\hline Lactobacillus salivarius UCC118 & gastrointestinal tract bacteria & NC_007929 \\
\hline Lactococcus lactis subsp. cremoris MG1363 & dairy fermentation & NC_009004 \\
\hline Lactococcus lactis subsp. cremoris SK11 & dairy fermentation & NC_008527 \\
\hline Lactococcus lactis subsp. lactis II1403 & dairy fermentation & NC_002662 \\
\hline Leuconostoc citreum KM20 & other fermentation such as beer, wine, plants, or meat & NC_010471 \\
\hline Leuconostoc mesenteroides subsp. mesenteroides ATCC 8293 & other fermentation such as beer, wine, plants, or meat & NC_008531 \\
\hline Oenococcus oeni PSU-1 & other fermentation such as beer, wine, plants, or meat & NC_008528 \\
\hline Pediococcus pentosaceus ATCC 25745 & dairy fermentation & NC_008525 \\
\hline Streptococcus gordonii str. Challis substr. $\mathrm{CH} 1$ & human oral flora (dental plaque) & NC_009785 \\
\hline Streptococcus mutans UA159 & oral streptococci (leading cause of dental caries) & NC_004350 \\
\hline Streptococcus thermophilus CNRZ1066 & dairy fermentation & NC_006449 \\
\hline Streptococcus thermophilus LMD-9 & dairy fermentation & NC_008532 \\
\hline
\end{tabular}

different selective constraints imposed by the functional categories that were involved in various metabolic networks [26-31].

Ranking single genes in six function categories by their respective phylogenetic resolution to LAB species reveals that 3 of 232 genes, including the ultra-violet resistance protein B gene $(u v r B)$ and the DNA polymerase III gene ( $p o l C$ ) from RRR category, and the penicillin binding protein $2 \mathrm{~B}$ gene $(p b p B)$ from CPS category (Additional file 2 Table S2), produced ML tree topology (Additional file 4 Figure S1a-1c) that was largely consistent with that of the complete analyses (Figure 1), albeit with low supports for some branches (BS $<70 \%)$. When we conducted the phylogenetic analyses by combining the three genes, a completely identical tree topology to that shown in Figure 1 with high supports for most of nodes was obtained. Therefore, a combined analysis using $u v r B$, polC and $p b p B$ together seems to be a better indicator for inferring LAB phylogeny than the other subset of genes including the ribosomal protein families or RNA polymerase subunits that have been widely used in previous LAB phylogenetic studies $[5-7,9,10]$. The Robinson-Foulds distances analysis (Additional file 3 Table S3) also showed that there are no differences between the tree of combined $u v r B$, polC and $p b p B$ genes and that of all concatenated genes. In the present study, the assessment of phylogenetic utility and limits of the individual genes makes it possible to preselect subsets of genes for future molecular studies of LAB phylogeny when the complete genome sequences are unavailable.

\section{Conclusions}

In this study, phylogenetic relationships among LAB species are presented based on 232 genes from 28 LAB genome sequences. The concatenation of all these genes allowed the recovery of a strongly supported phylogeny, providing a maximum and decisive resolution of the relationships among the LAB species examined. Our phylogenomic analyses provide important insights into not only LAB phylogeny, but also the phylogenetic utility of different genes suggesting that the genes relating 


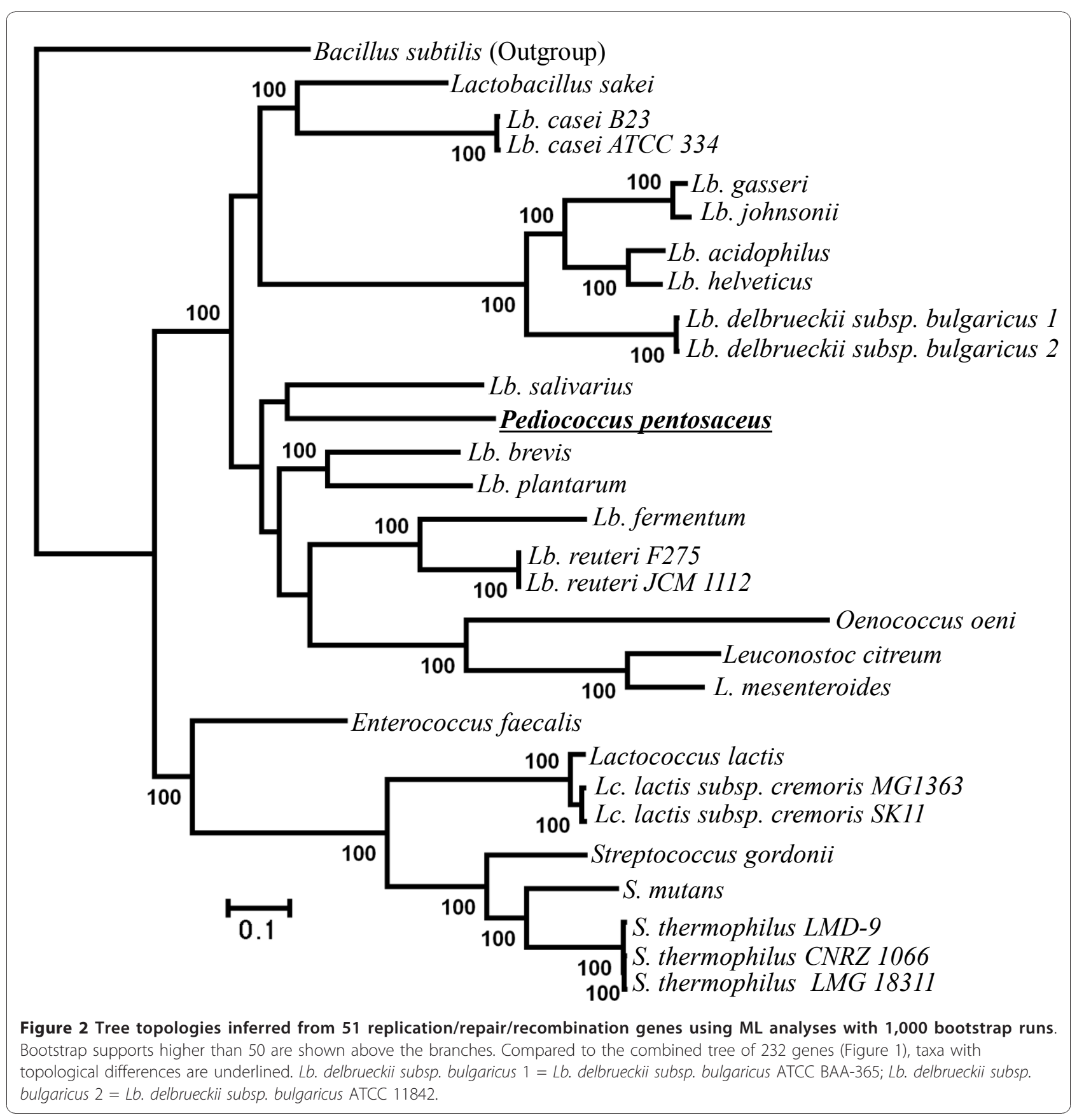

to translation, ribosomal structure and biogenesis (TRSB) function and a three-gene set consisting of $u v r B$, polC and $p b p B$, may be better indicators for LAB phylogenetic studies than the other subsets of genes. In addition, our study demonstrates the presence of multiple independent adaption events of LAB species to different survival habitats, indicating that further analyses of more genes from representatives of additional LAB species are needed in order to reveal the molecular mechanisms underlying the adaptation of LAB species to various environmental survival niches.

\section{Methods}

Sequence Data

A total of 28 available LAB genomes [6,9,32-44] representing seven genera of four families were used (Table 1). In addition, the genome sequence from Bacillus subtilis was used as an outgroup to root the tree. 


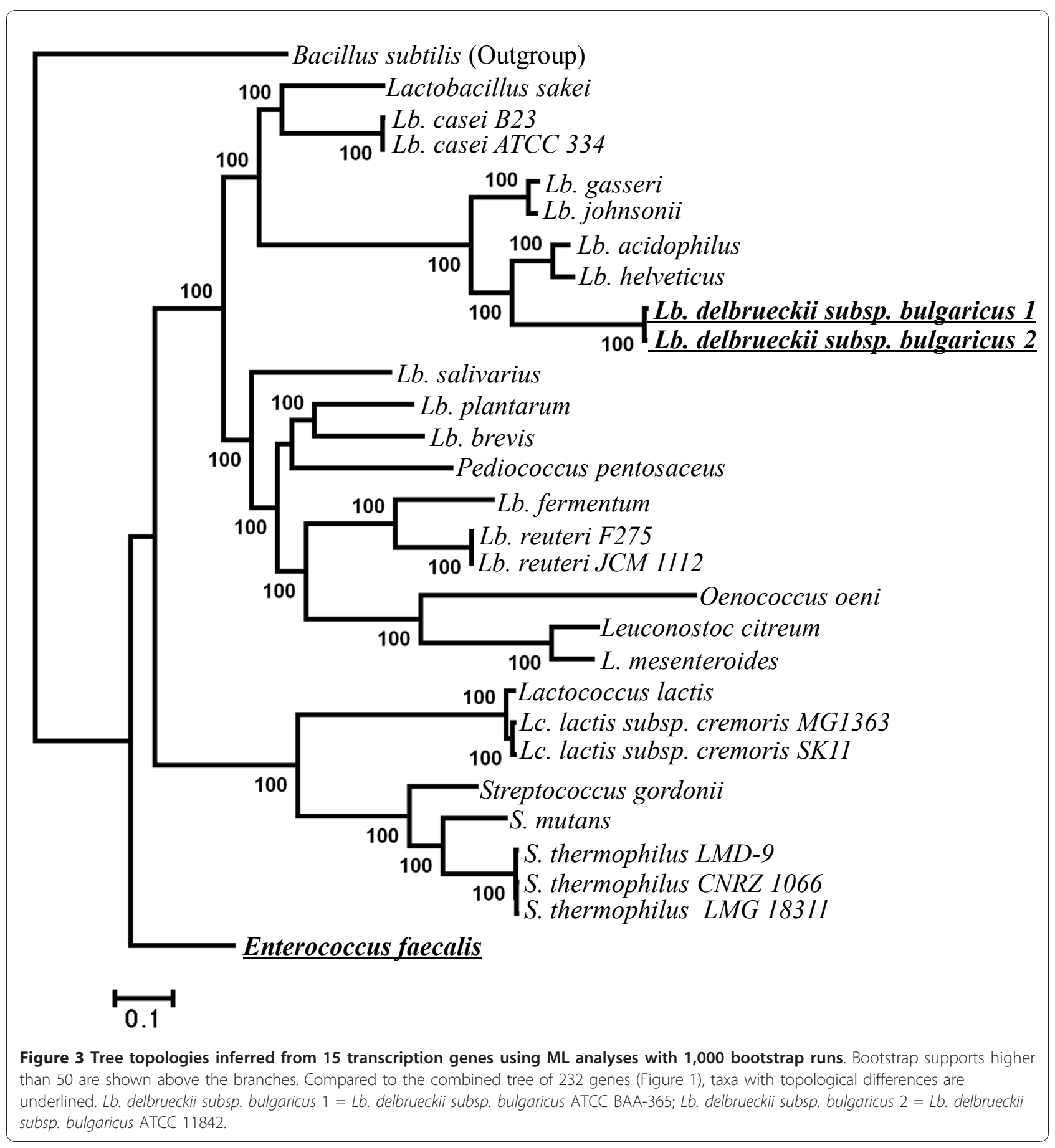

Identification of one-to-one orthologs for LAB phylogenetic inference

Based on protein coding genes (pseudogenes are not included) downloaded from $28 \mathrm{LAB}$ and one B. subtilis genome sequences, a search for orthologs was conducted with the program Inparanoid version 2.0 [14]. Several stringent criteria were employed: (1) using a BLAST score cut-off of 50 bits; (2) using an overlap cut-off of $50 \%$; (3) using a confidence value of $95 \%$ when searching in-paralogs; (4) using BLOSUM45 amino acid substitution matrix [45]. Automatic clustering of orthologs and inparalogs identified by the program Inparanoid was then performed by program Multiparanoid [15].

Among the candidate orthologous genes selected as above, we excluded those that met the following criteria 


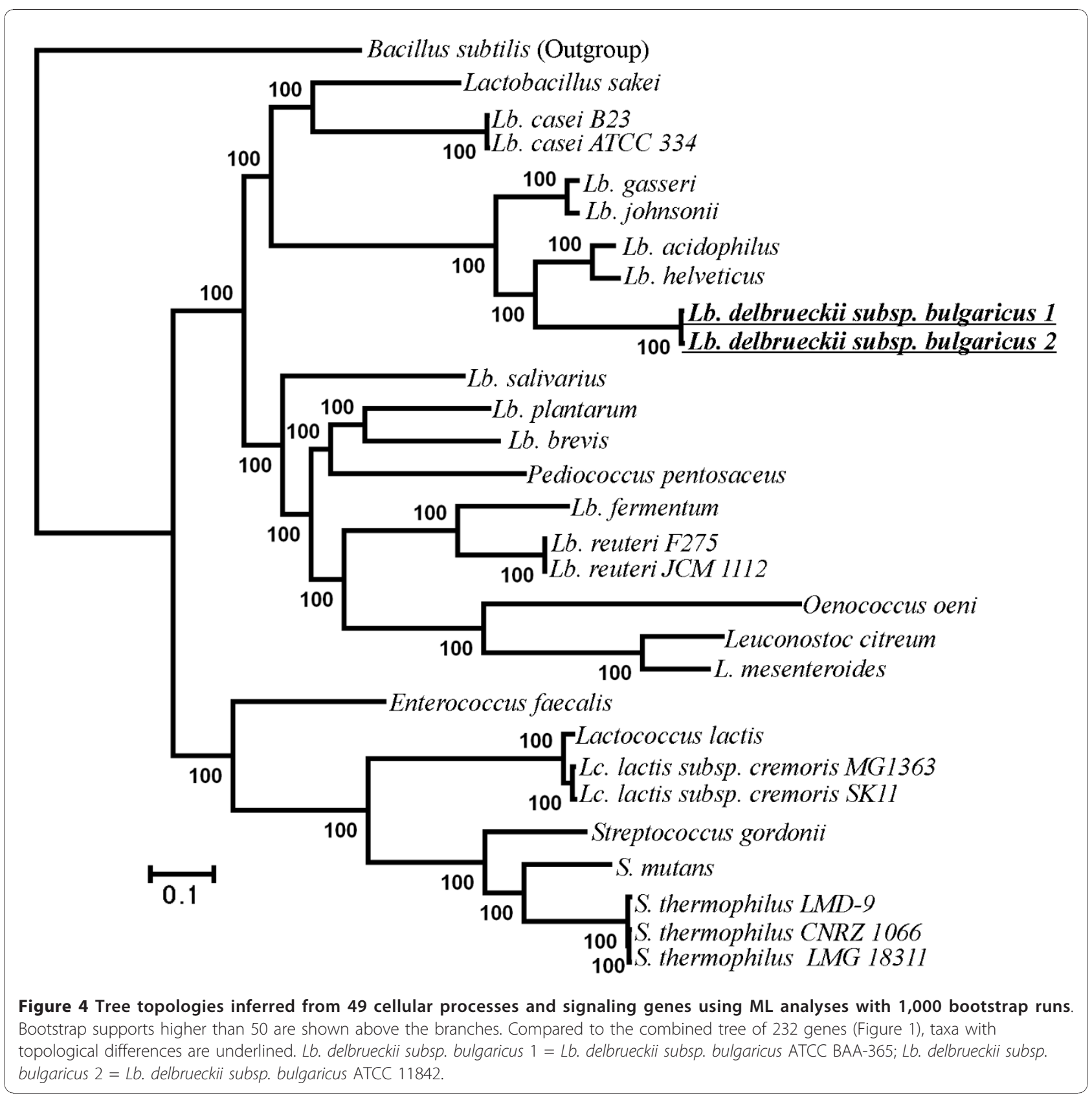

from subsequent analyses: (1) lesser than 100 amino acid sequence length; (2) involved in potential horizontal gene transfer (HGT) events, as predicted by Horizontal Gene Transfer Database (HGT-DB) http://genomes.urv. es/HGT-DB/ and http://www.tinet.org/ debb/HGT/welcomeOLD.html and by previous studies [6]. In the end, a total of 232 orthologous genes, including 225 that have clear functional definition and 7 that have been annotated to be hypothetical proteins, were used to reconstruct LAB phylogeny in this study (Additional file 2 Table S2).
Phylogenetic Reconstruction of LAB species

In total 232 orthologous genes were concatenated into two supermatrices according to two gap selection criteria in Gblocks [allowed gap positions = none $(61,020$ amino acids in length) and with half (only positions where $50 \%$ or more of the sequences have a gap are treated as a gap position in the final alignment) $(63,910$ amino acids in length)] [46]. Optimal substitution models were selected by using the program ProtTest version 2.4 [47] according to Akaike Information Criterion (AIC) [48]. The selected substitution models were used 


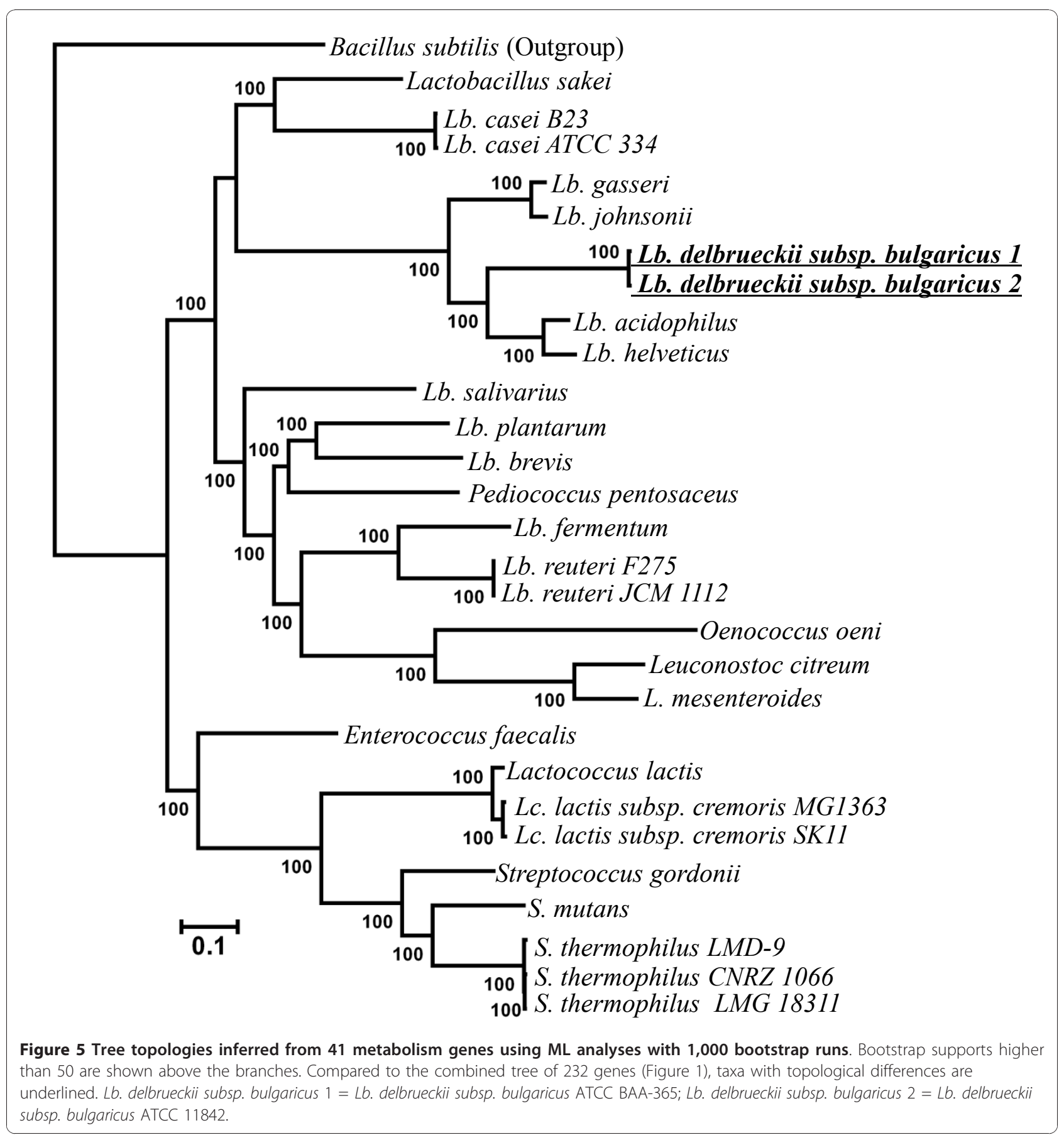

in partitioned Bayesian analysis implemented MrBayes v3.2.1 [49-51] and partitioned maximum likelihood (ML) analysis implemented in RAxML v7.0.4 [52]. The reliability of ML tree topology was evaluated by bootstrapping sampling (BP) of 1000 replicates. For Bayesian analyses, three independent runs of one-million generations each were used. The trees sampled prior to reaching convergence were discarded as burn-in and the remaining trees were used to construct the consensus tree and posterior probabilities (PP).

\section{Tree topology comparison}

The differences between tree topologies were compared using Robinson-Foulds distances that were calculated with program Treedist from the PHYLIP v3.69 package [53]. 


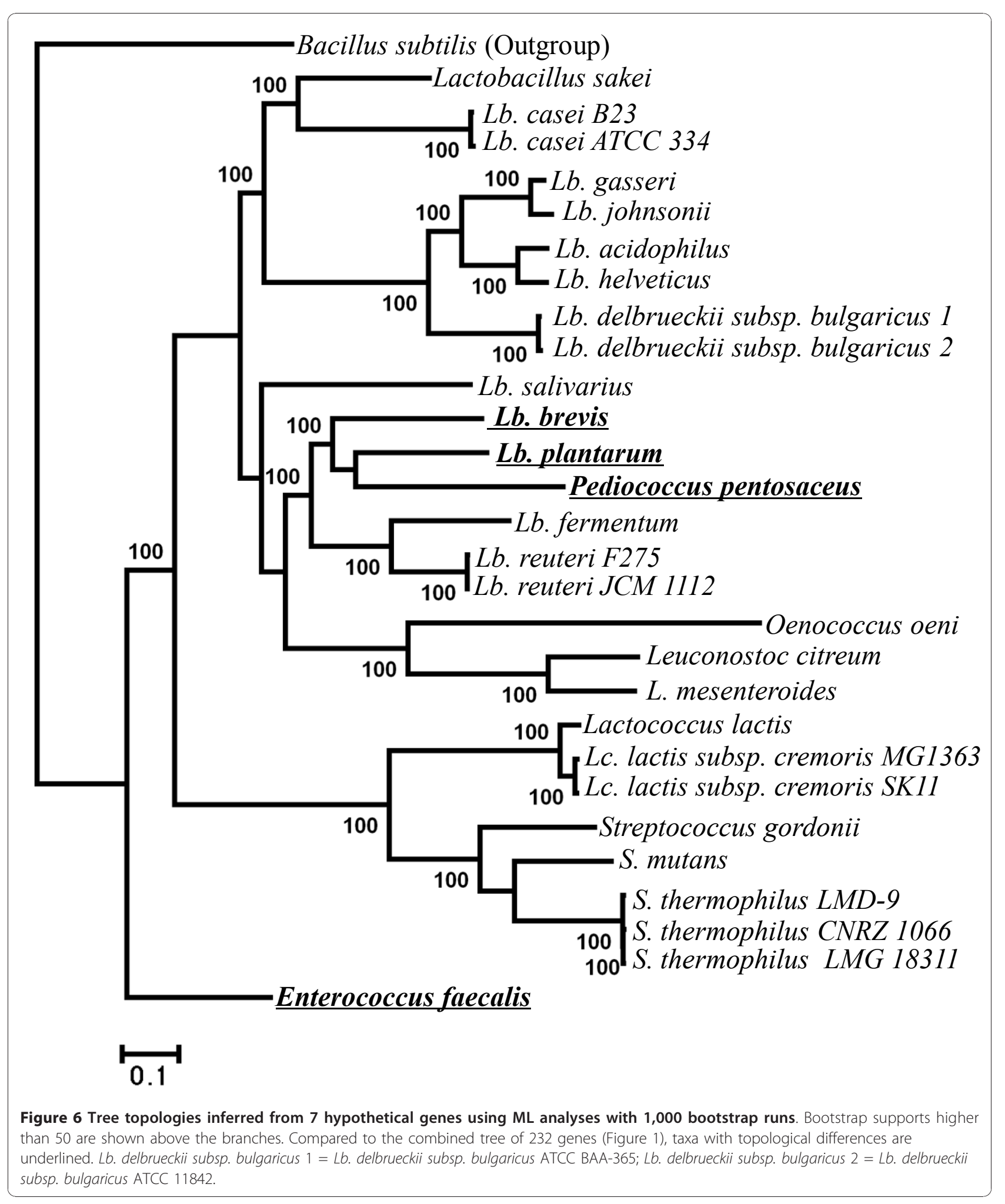




\section{Additional material}

Additional file 1: Table S1. Summary of 310 one-to-one orthologs from 28 LAB species and one outgroup (Bacillus subtilis).

Additional file 2: Table S2. Summary of 232 one-to-one orthologs used in $L A B$ phylogenomic inference and their functional categories based on COG annotation.

Additional file 3: Table S3. Robinson-Foulds distances between different tree topologies.

Additional file 4: Figure S1. Single gene trees inferred from ML analyses with 1,000 replicates.

\section{Acknowledgements}

Special thanks to members of the Shi lab and two anonymous reviewers for valuable comments and Dong-Qiang Chen for technical assistance. This work was supported by grants from General Program of Natural Science Foundation of Yunnan Province of China (Grant No. 2009CD108) and by a start-up fund of "Hundreds Talent Program" from Chinese Academy of Sciences to P.S.

\section{Author details}

'State Key Laboratory of Genetic Resources and Evolution, Laboratory of Evolutionary and Functional Genomics, Kunming Institute of Zoology, Chinese Academy of Sciences, Kunming 650223, PR China. ' Laboratory for Conservation and Utilization of Bio-resource \& Key Laboratory for Microbial Resources, Ministry of Education, Yunnan University, PR China. ${ }^{3}$ Graduate School of the Chinese Academy of Sciences, Beijing, PR China.

\section{Authors' contributions}

$Z Z$ and PS designed the study. ZZ, ZY, LY and PS analyzed the data and wrote the manuscript. All the authors have read and approved the final manuscript.

Received: 30 June 2010 Accepted: 1 January 2011

Published: 1 January 2011

\section{References}

1. Euzéby JP: List of bacterial names with standing in nomenclature: a folder available on the internet. Int J Syst Bacteriol 1997, 47:590-592[http:// www.bacterio.cict.fr/index.html].

2. Salminen S, von Wright A, Ouwehand Ae: Lactic Acid Bacteria: Microbiological and Functional Aspects (3rd ed.) Revised and Expanded Edition. Marcel Dekker Inc, New York; 2004.

3. Collins MD, Rodrigues U, Ash C, Aguirre M, Farrow JAE, Martinez-Murcia A Phillips BA, Williams AM, Wallbanks S: Phylogenetic analysis of the genus Lactobacillus and related lactic acid bacteria as determined by reverse transcriptase sequencing of 16 S rRNA. FEMS Microbiology Letters 1991, 77(1):5-12.

4. Carr FJ, Chill D, Maida N: The lactic acid bacteria: a literature survey. Crit Rev Microbiol 2002, 28(4):281-370.

5. Makarova KS, Koonin EV: Evolutionary genomics of lactic acid bacteria. $J$ Bacteriol 2007, 189(4):1199-1208.

6. Makarova K, Slesarev A, Wolf Y, Sorokin A, Mirkin B, Koonin E, Pavlov A, Pavlova N, Karamychev V, Polouchine N, et al: Comparative genomics of the lactic acid bacteria. Proc Natl Acad Sci USA 2006, 103(42):15611-15616.

7. Liu M, Nauta A, Francke C, Siezen RJ: Comparative genomics of enzymes in flavor-forming pathways from amino acids in lactic acid bacteria. Appl Environ Microbiol 2008, 74(15):4590-4600.

8. Claesson MJ, van Sinderen D, OToole PW: Lactobacillus phylogenomics towards a reclassification of the genus. Int J Syst Evol Microbiol 2008, 58(12):2945-2954.

9. Callanan M, Kaleta P, O'Callaghan J, O'Sullivan O, Jordan K, McAuliffe O, Sangrador-Vegas A, Slattery L, Fitzgerald GF, Beresford T, et al: Genome sequence of Lactobacillus helveticus, an organism distinguished by selective gene loss and insertion sequence element expansion. J Bacteriol 2008, 190(2):727-735.
10. Cai H, Thompson R, Budinich M, Broadbent JR, Steele JL: Genome sequence and comparative genome analysis of Lactobacillus casei: insights into their niche-associated evolution. Genome Biol Evol 2009, evp019.

11. Berger B, Pridmore RD, Barretto C, Delmas-Julien F, Schreiber K, Arigoni F, Brussow $\mathrm{H}$ : Similarity and differences in the Lactobacillus acidophilus group identified by polyphasic analysis and comparative genomics. $J$ Bacteriol 2007, 189(4):1311-1321.

12. Ventura M, O'Flaherty $\mathrm{S}$, Claesson MJ, Turroni F, Klaenhammer TR, van Sinderen D, O'Toole PW: Genome-scale analyses of health-promoting bacteria: probiogenomics. Nat Rev Micro 2009, 7(1):61-71.

13. Delsuc $F$, Brinkmann $H$, Philippe $H$ : Phylogenomics and the reconstruction of the tree of life. Nat Rev Genet 2005, 6(5):361-375.

14. Remm M, Storm CEV, Sonnhammer ELL: Automatic clustering of orthologs and in-paralogs from pairwise species comparisons. Journal of Molecular Biology 2001, 314(5):1041-1052.

15. Alexeyenko A, Tamas I, Liu G, Sonnhammer ELL: Automatic clustering of orthologs and inparalogs shared by multiple proteomes. Bioinformatics 2006, 22(14):e9-15

16. Tatusov R, Fedorova N, Jackson J, Jacobs A, Kiryutin B, Koonin E, Krylov D, Mazumder R, Mekhedov S, Nikolskaya A, et al: The COG database: an updated version includes eukaryotes. BMC Bioinformatics 2003, 4(1):41.

17. Li L, Stoeckert CJ, Roos DS: OrthoMCL: Identification of ortholog groups for eukaryotic genomes. Genome Research 2003, 13(9):2178-2189.

18. Fraser AG, Marcotte EM: A probabilistic view of gene function. Nat Genet 2004, 36(6):559-564.

19. Kopelman NM, Lancet $D$, Yanai I: Alternative splicing and gene duplication are inversely correlated evolutionary mechanisms. Nat Genet 2005, 37(6):588-589.

20. Rhodes DR, Tomlins SA, Varambally S, Mahavisno V, Barrette T, KalyanaSundaram S, Ghosh D, Pandey A, Chinnaiyan AM: Probabilistic model of the human protein-protein interaction network. Nat Biotech 2005, 23(8):951-959.

21. Stelzl U, Worm U, Lalowski M, Haenig C, Brembeck FH, Goehler H Stroedicke M, Zenkner M, Schoenherr A, Koeppen S, et al: A Human protein-protein interaction network: a resource for annotating the proteome. Cell 2005, 122(6):957-968.

22. Kawamura Y, Hou X-G, Sultana F, Miura H, Ezaki T: Determination of $16 \mathrm{~S}$ rRNA sequences of Streptococcus mitis and Streptococcus gordonii and phylogenetic relationships among members of the genus Streptococcus. Int J Syst Bacteriol 1995, 45(2):406-408.

23. Naser SM, Dawyndt P, Hoste B, Gevers D, Vandemeulebroecke K, Cleenwerck I, Vancanneyt M, Swings J: Identification of lactobacilli by pheS and $r p \circ A$ gene sequence analyses. International Journal of Systematic and Evolutionary Microbiology 2007, 57(12):2777-2789.

24. Marco ML, de Vries MC, Wels M, Molenaar D, Mangell P, Ahrne S, de Vos WM, Vaughan EE, Kleerebezem M: Convergence in probiotic Lactobacillus gut-adaptive responses in humans and mice. ISME J 2010.

25. Siezen RJ, Tzeneva VA, Castioni A, Wels M, Phan HTK, Rademaker JLW, Starrenburg MJC, Kleerebezem M, Molenaar D, Van Hylckama Vlieg JET: Phenotypic and genomic diversity of Lactobacillus plantarum strains isolated from various environmental niches. Environmental Microbiology 2010, 12(3):758-773.

26. Tourasse NJ, Li W-H: Selective constraints, amino acid composition, and the rate of protein evolution. Molecular Biology and Evolution 2000, 17(4):656-664.

27. KIMURA M: The neutral theory of molecular evolution. Cambridge University Press, Cambridge, England; 1983.

28. LI W-H: Molecular evolution. Sinauer, Sunderland, Mass; 1997

29. NEI M: Molecular evolutionary genetics. Columbia University Press, New York; 1987.

30. Greenberg AJ, Stockwell SR, Clark AG: Evolutionary constraint and adaptation in the metabolic network of drosophila. Molecular Biology and Evolution 2008, 25(12):2537-2546.

31. Castillo-Ramirez S, Gonzalez V: Factors affecting the concordance between orthologous gene trees and species tree in bacteria. BMC Evolutionary Biology 2008, 8(1):300.

32. Ajdić D, McShan WM, McLaughlin RE, Savić G, Chang J, Carson MB, Primeaux C, Tian R, Kenton S, Jia H, et al: Genome sequence of Streptococcus mutans UA159, a cariogenic dental pathogen. Proc Natl Acad Sci USA 2002, 99(22):14434-14439. 
33. Altermann E, Russell WM, Azcarate-Peril MA, Barrangou R, Buck BL, McAuliffe O, Souther N, Dobson A, Duong T, Callanan M, et al: Complete genome sequence of the probiotic lactic acid bacterium Lactobacillus acidophilus NCFM. Proc Natl Acad Sci USA 2005, 102(11):3906-3912.

34. Bolotin A, Quinquis B, Renault P, Sorokin A, Ehrlich SD, Kulakauskas S, Lapidus A, Goltsman E, Mazur M, Pusch GD, et al: Complete sequence and comparative genome analysis of the dairy bacterium Streptococcus thermophilus. Nat Biotech 2004, 22(12):1554-1558.

35. Chaillou S, Champomier-Verges MC, Cornet M, Crutz-Le Coq AM, Dudez AM, Martin V, Beaufils S, Darbon-Rongere E, Bossy R, Loux V, et al: The complete genome sequence of the meat-borne lactic acid bacterium Lactobacillus sakei 23 K. Nat Biotechnol 2005, 23(12):1527-1533.

36. Claesson MJ, Li Y, Leahy S, Canchaya C, van Pijkeren JP, CerdeñoTárraga AM, Parkhill J, Flynn S, O'Sullivan GC, Collins JK, et al: Multireplicon genome architecture of Lactobacillus salivarius. Proc Natl Acad Sci USA 2006, 103(17):6718-6723.

37. Kim JF, Jeong H, Lee J-S, Choi S-H, Ha M, Hur C-G, Kim J-S, Lee S, Park H-S, Park Y-H, et al: Complete genome sequence of Leuconostoc citreum KM20. J Bacteriol 2008, 190(8):3093-3094.

38. Kleerebezem M, Boekhorst J, van Kranenburg R, Molenaar D, Kuipers OP, Leer R, Tarchini R, Peters SA, Sandbrink HM, Fiers MW, et al: Complete genome sequence of Lactobacillus plantarum WCFS1. Proc Natl Acad SCi USA 2003, 100(4):1990-1995.

39. Kunst F, Ogasawara N, Moszer I, Albertini AM, Alloni G, Azevedo V, Bertero MG, Bessieres P, Bolotin A, Borchert S, et al: The complete genome sequence of the gram-positive bacterium Bacillus subtilis. Nature 1997 390(6657):249-256.

40. Morita H, Toh H, Fukuda S, Horikawa H, Oshima K, Suzuki T, Murakami M, Hisamatsu S, Kato Y, Takizawa $T$, et al: Comparative genome analysis of Lactobacillus reuteri and Lactobacillus fermentum reveal a genomic island for reuterin and cobalamin production. DNA Res 2008, 15(3):151-161.

41. Paulsen IT, Banerjei L, Myers GSA, Nelson KE, Seshadri R, Read TD, Fouts DE, Eisen JA, Gill SR, Heidelberg JF, et al: Role of mobile DNA in the evolution of vancomycin-resistant Enterococcus faecalis. Science 2003, 299(5615):2071-2074.

42. Pridmore RD, Berger B, Desiere F, Vilanova D, Barretto C, Pittet A-C, Zwahlen M-C, Rouvet M, Altermann E, Barrangou R, et al: The genome sequence of the probiotic intestinal bacterium Lactobacillus johnsonii NCC 533. Proc Natl Acad Sci USA 2004, 101(8):2512-2517.

43. van de Guchte M, Penaud S, Grimaldi C, Barbe V, Bryson K, Nicolas P, Robert C, Oztas S, Mangenot S, Couloux A, et al: The complete genome sequence of Lactobacillus bulgaricus reveals extensive and ongoing reductive evolution. Proc Natl Acad Sci USA 2006, 103(24):9274-9279.

44. Wegmann U, O'Connell-Motherway M, Zomer A, Buist G, Shearman C, Canchaya C, Ventura M, Goesmann A, Gasson MJ, Kuipers OP, et al: Complete genome sequence of the prototype lactic acid bacterium Lactococcus lactis subsp. cremoris MG1363. J Bacteriol 2007, 189(8):3256-3270.

45. Henikoff $S$, Henikoff JG: Amino acid substitution matrices from protein blocks. Proc Natl Acad Sci USA 1992, 89(22):10915-10919.

46. Castresana J: Selection of conserved blocks from multiple alignments for their use in phylogenetic analysis. Mol Biol Evol 2000, 17(4):540-552.

47. Abascal F, Zardoya R, Posada D: ProtTest: selection of best-fit models of protein evolution. Bioinformatics 2005, 21(9):2104-2105.

48. Akaike $\mathrm{H}$ : Information theory and an extension of the maximum likelihood principle. Proceedings of 2nd International Symposium on Information Theory, Budapest, Hungary 1973, 267-281.

49. Altekar G, Dwarkadas S, Huelsenbeck JP, Ronquist F: Parallel Metropoliscoupled Markov chain Monte Carlo for Bayesian phylogenetic inference. Bioinformatics 2004, 20(3):407-415

50. Huelsenbeck JP, Ronquist F, Nielsen R, Bollback JP: Bayesian inference of phylogeny and its impact on evolutionary biology. Science 2001, 294(5550):2310-2314.

51. Nylander JAA, Ronquist F, Huelsenbeck JP, Nieves-Aldrey J: Bayesian phylogenetic analysis of combined Data. Syst Biol 2004, 53(1):47-67.

52. Ott M, Zola J, Stamatakis A, Aluru S: Large-scale maximum likelihoodbased phylogenetic analysis on the IBM BlueGene/L. Proceedings of the 2007 ACM/IEEE conference on Supercomputing Reno, Nevada: ACM; 2007, $1-11$.
53. Felsenstein J: PHYLIP (Phylogeny Inference Package) version 3.6. Distributed by the author Department of Genome Sciences, University of Washington, Seattle 2005.

doi:10.1186/1471-2148-11-1

Cite this article as: Zhang et al:: Phylogenomic reconstruction of lactic acid bacteria: an update. BMC Evolutionary Biology 2011 11:1.

\section{Submit your next manuscript to BioMed Central and take full advantage of:}

- Convenient online submission

- Thorough peer review

- No space constraints or color figure charges

- Immediate publication on acceptance

- Inclusion in PubMed, CAS, Scopus and Google Scholar

- Research which is freely available for redistribution

Submit your manuscript at www.biomedcentral.com/submit
C Biomed Central 